\title{
Hydroclimatological influences on recently increased droughts in China's largest freshwater lake
}

\author{
Y. Liu and G. Wu \\ Nanjing Institute of Geography \& Limnology, Chinese Academy of Sciences, 73 East Beijing Road, \\ Nanjing 210008, China \\ Correspondence to: Y. Liu (ybliu@niglas.ac.cn; yb218@yahoo.com)
}

Received: 22 February 2014 - Published in Hydrol. Earth Syst. Sci. Discuss.: 28 May 2014

Revised: 3 December 2015 - Accepted: 18 December 2015 - Published: 15 January 2016

\begin{abstract}
Lake droughts are the consequence of climatic, hydrologic and anthropogenic influences. Quantification of droughts and estimation of the contributions from the individual factors are essential for understanding drought features and their causation structure. This is also important for policymakers to make effective adaption decisions, especially under changing climate. This study examines Poyang Lake, China's largest freshwater lake, which has been undergoing drastic hydrological alternation in the past decade. Standardized lake stage is used to identify and quantify the lake droughts, and hydroclimatic contributions are determined with a water budget analysis, in which absolute deficiency is defined in reference to normal hydrologic conditions. Our analyses demonstrate that in the past decade the lake droughts worsened in terms of duration, frequency, intensity and severity. Hydroclimatic contributions to each individual drought varied between droughts, and the overall contribution to the lake droughts in the past decade came from decreased inflow, increased outflow, and reduced precipitation and increased evapotranspiration in the lake region. The decreased inflow resulted mainly from reduced precipitation and less from increased evapotranspiration over the Poyang Lake basin. The increased outflow was attributable to the weakened blocking effects of the Yangtze River, which the Three Gorges Dam (TGD) established upstream. The TGD impoundments were not responsible for the increased number of drought events, but they may have intensified the droughts and changed the frequency of classified droughts. However, the TGD contribution is limited in comparison with hydroclimatic influences. Hence, the recently increased droughts were due to hydroclimatic effects, with a less important contribution from anthropogenic influences.
\end{abstract}

\section{Introduction}

A drought is a temporary lack of water caused by abnormal climatic or environmental influences, among other factors (Kallis, 2008; Mishra and Singh, 2010; and references therein). There are meteorological droughts (abnormal precipitation deficits), hydrological droughts (abnormal streamflow, groundwater, or lake deficits), agricultural droughts (abnormal soil moisture deficits), ecological droughts (abnormal water deficits causing stress on ecosystems) and socio-economic droughts (abnormal failures of water supply to meet economic and social demands) (Tallaksen and van Lanen, 2004; Kallis, 2008; Mishra and Singh, 2010). The drought phenomena may have different temporal features and causation structures (Kallis, 2008; Mishra and Singh, 2010). It is anticipated that droughts would likely increase owing to global climate change (Kallis, 2008; Mishra and Singh, 2010).

Hydrological droughts occur when land-water resources decrease significantly below normal conditions, represented by low water levels in streams, lakes, reservoirs and groundwater as well (Nalbantis and Tsakiris, 2009; Keskin and Sorman, 2010). Streamflow droughts may occur with basinscale precipitation deficiency and/or excessive evapotranspiration (Zelenhasic and Salvai, 1987; Tallaksen et al., 1997; Kingston et al., 2013). In addition to local precipitation and evaporation, lake droughts involve other hydrological components, including inflows from streams surrounding the lake and outflows out of the lake. Hence, lake droughts can be more complicated than streamflow droughts in causation structure. Furthermore, both inflows and outflows may be affected by human activities, for example, groundwater pumping, reservoir construction or land cover change (Wilcox 
et al., 2010). Therefore, lake droughts are the consequence of combined climatic, hydrologic and anthropogenic influences. In contrast to floods that have received a great deal of attention in hydrology, droughts are not yet comprehensively understood (Kallis, 2008; Mishra and Singh, 2011). Quantification of lake droughts and clarification of contributions from individual factors are essential for understanding drought features and their causation structure. This is important for policymakers to make effective adaption decisions, especially under changing climate. Site-based drought analysis is a starting point towards integrated theories of drought (Kallis, 2008).

Poyang Lake is China's largest freshwater lake, which has been undergoing hydrological alterations in recent decades (Jiao, 2009; Finlayson et al., 2010; Hervé et al., 2011; Liu et al., 2013; Zhang et al., 2014). The lake is located at the south bank of the Yangtze River, which is a humid monsoon climatic region. Although the region historically experiences significant floods (Shankman and Liang, 2003; Shankman et al., 2006), severe lake droughts have occurred frequently in the past decade, resulting in tremendous hydrological, biological, ecological and economic consequences (Feng et al., 2012; Environment News Service, 2012; Wu and Liu, 2014). Because the lake is the primary part of the well-known Poyang Lake wetland and the lake region serves as an important food base for China, the frequently occurring lake droughts have also received increasing international attention (Jiao, 2009; Finlayson et al., 2010; Liu et al., 2011; Environment News Service, 2012; The Ramsar Convention, 2012; Zhang et al., 2012, 2014).

Lake droughts are usually defined as an abnormal decline in lake stage or lake size. A number of studies have documented this decline in Poyang Lake and its influencing factors (Guo et al., 2012; Zhang et al., 2012; Liu et al., 2013; Lai et al., 2014a; Zhang et al., 2014). Feng et al. (2012) used satellite images with a $250 \mathrm{~m}$ spatial resolution and reported that the lake size had a decreasing trend between 2000 and 2010. Liu et al. (2013) revealed an abrupt decrease in the lake size in 2006, mainly in October and November. Zhang et al. (2014) demonstrated that the lake stage fell to its lowest level during the 2000s compared to previous decades, in particular in the autumn recession periods. Since Poyang Lake receives inflows from its surrounding basin and discharges into the Yangtze River via a narrow outlet at the Hukou (Fig. 1), the strong lake-river interaction makes it complex to separate relative impacts of the inflow and outflow on the lake stage (Hu et al., 2007; Lai et al., 2014a). Zhang et al. (2014) employed a hydrodynamic model for Poyang Lake for the separation and declared that the lake decline in the 2000s was primarily ascribed to the weakened blocking effect of the Yangtze River. Compared to climate variability on the lake basin, modifications to the Yangtze River flows have had a much greater influence on the seasonal (September-October) dryness of the lake (Zhang et al., 2014). The modification was largely attributable to the operation of the Three Gorges
Dam (TGD), established upstream of the Yangtze River in 2003. Water impoundments of the TGD incurred water level drops with an average estimate of $2 \mathrm{~m}$ at the outlet of Poyang Lake in mid-September to November for the period 20032008 (Guo et al., 2012; Zhang et al., 2012). Alternatively, Lai et al. (2013) developed a hydrodynamic model for the middle Yangtze River region (CHAM-Yangtze), in which they coupled both Poyang Lake and the Yangtze River to account for the lake-river interactions explicitly. They demonstrated that the lake stage was more sensitive to the alternation in lake inflow compared to the same discharge modification in the Yangtze River (Lai et al., 2014a). The recent extremely low water levels in the Yangtze River resulted mainly from remarkable declines in inflows to the river, rather than solely from the TGD impoundments (Lai et al., 2014b). These studies highlighted the complexity of the multiple influences on Poyang Lake's decline in the complex basin-lake-river system.

Drought differs from low water level and persistent dryness. Water level can be low in seasonal dry seasons, but this does not necessarily constitute a drought (Smakhtin, 2001). Persistent dryness refers to water decrease in a long run, which is usually unrecoverable in the short term (Zhang et al., 2012). Droughts are complex events that have a recurrent feature, and may occur in any season and last several months or longer (Todd et al., 2013). Feng et al. (2012) quantified the drought severity of Poyang Lake in 2011 and showed that the drought was primarily due to low basin-scale precipitation, rather than discharge differences between the lake and the Yangtze River with TGD impoundments. Very recently, $\mathrm{Wu}$ and Liu (2014) used satellite-delineated inundation area to quantify two lake droughts in 2006 and 2011. The results indicated that the 2006 drought was mainly attributable to abnormal decrease of water flow in the Yangtze River and the 2011 drought was due to the combined influences of the Poyang Lake basin and the Yangtze River. Although these were two extreme drought events, it is not certain if they explain the more frequently occurring droughts in Poyang Lake as well.

In principle, drought identification, quantification or characterization with a consistent standard is a prerequisite for drought analysis. However, few studies have comprehensively quantified and addressed the Poyang Lake droughts in the 2000s. The current understanding of the Lake's decline in autumn cannot provide a complete explanation to the lake droughts spanning non-autumn seasons. It remains unknown to what extent the climatic, hydrologic and anthropogenic influences have contributed to the lake droughts, which is one of the key issues for developing integrated, interdisciplinary theories on droughts (Kallis, 2008). Especially for practice, clarification of the multiple influences on the recently increased droughts is essential for the effective prevention of droughts.

The complicated causality of lake droughts requires a robust approach for determining the contributions from mul- 
tiple influences. Analogous to standardized precipitation index, this study utilizes standardized lake index to quantify lake droughts. With the principle of lake water balance, it proposes to define an absolute deficiency for each water component and determine their relative contributions to lake droughts. The approach is applicable to basin-scale water balance, quantifying regional hydroclimatic influences on lake inflow, and subsequently on lake droughts (Sect. 2). Poyang Lake droughts are examined with the proposed approach, in combination with 5-decade hydroclimatic data including the latest satellite products (Sect. 3). The drought features in the 2000s and their causes are subsequently addressed (Sect. 4). Our findings should be valuable for improving our understanding of lake droughts under changing climate conditions and be useful for local water resources management and climate change adaptation.

\section{Methodology}

The main properties of a drought are time of initiation and termination, duration, severity, magnitude and intensity, as well as spatial extent in the case of meteorological or agricultural droughts (Yevjevich, 1967; Dracup et al., 1980; Wilhite and Glantz, 1985; McKee et al., 1993; Mishra and Singh, 2010; Spinoni et al., 2014). Drought initiation time is the beginning of the drought. Termination time is the end, i.e., when the drought ceases. Drought duration is the period between the initiation and the termination (Yevjevich, 1967; Mishra and Singh, 2010). Drought severity is the total, cumulative water deficiency for the duration of the drought. Drought magnitude is a derivative of drought severity, defined as the average water deficit in the drought period (Dracup et al., 1980; Wilhite and Glantz, 1985). Drought intensity usually refers to the largest departure from the normal conditions (McKee et al., 1993; Spinoni et al., 2014). For a given historical period, another important drought statistic is drought frequency, which refers to the number of drought events that have occurred (Mishra and Singh, 2010; Spinoni et al., 2014).

\subsection{Quantification of lake droughts}

Various indices have been proposed to characterize and quantify the complex features of droughts (Dracup et al., 1980; Keyantash and Dracup, 2002; Mishra and Singh, 2010, 2011). Among these, the standardized precipitation index (SPI) is most commonly used (McKee et al., 1993; Mishra and Singh, 2010). It is a normalized dimensionless index, defined as the difference of precipitation from the mean divided by the standard deviation for a given period, in which a gamma distribution is generally fitted to the long-term precipitation records for each calendar month to account for seasonal differences (McKee et al., 1993). The SPI is simple but capable of quantifying drought features, and has been re- cently recommended by the World Meteorological Organization (WMO) to characterize meteorological droughts (Hayes et al., 2011). Nevertheless, it was proposed to quantify precipitation deficiency, the SPI methodology has been applied in a similar manner to other hydroclimatic variables, for example, streamflow discharge, soil moisture, reservoir storage and groundwater level (McKee et al., 1993; Sheffield et al., 2004; Vicente-Serrano and López-Moreno, 2005; Mendicino et al., 2008; Shukla and Wood, 2008).

In the case of lake drought, it can be described with lake stage, lake area or water storage. Of these variables, lake stage is usually continuously measured and is suitable for drought analysis. In comparison to SPI, the standardized lake index (SLI) is described as follows

$\operatorname{SLI}_{i j}=\frac{L_{i j}-\bar{L}_{j}}{\sigma_{j}}$

where $L_{i j}$ is the monthly average lake stage (unit in meters) of year $i$ and month $j(j=1,2, \ldots, 12)$, which is transformed from gamma distribution into the normal distribution (McKee et al., 1993). $\bar{L}_{j}$ is the multi-year mean of monthly average stage for month $j$, and $\sigma_{j}$ is the standard deviation of monthly average stage for month $j$. Since SLI uses $\bar{L}_{j}$ and $\sigma_{j}$, both of which are monthly dependent, it removes seasonal differences in the lake stage.

A drought event is discernible with SLI. While a negative SLI indicates the lake stage is lower than the normal, not all the negatives can be classified into a drought event. Only when SLI deviates away from the normal by more than 1 standard deviation (SLI $<-1$ ), an event can be established (McKee et al., 1995). Furthermore, a drought initializes when SLI becomes negative and terminates before SLI becomes positive in SLI time series (McKee et al., 1995). The initialization and the termination time yield drought duration (unit in day, month or year). Once all the drought events are identified, drought frequency can be determined for a given period.

In accordance with the definition of SPI by McKee et al. (1993), SLI represents a departure of lake stage from its normal conditions. The departure corresponds to a probability of drought intensity, useful for drought risk analysis, namely, SLI $=-1$ denotes an occurrence probability of $15.9 \%$ (Lloyd-Hughes and Saunders, 2002). Positive (negative) value indicates lake stage higher (lower) than the normal condition for the period. For an individual drought event, its lowest SLI value indicates the intensity of the event (McKee et al., 1993; Spinoni et al., 2014). Accordingly, a drought event can be classified into four categories with its lowest SLI: extreme drought $(-\infty,-2.0]$, severe drought $(-2.0$, $-1.5]$, moderate drought $(-1.5,-1.0]$ and mild drought $(-1.0,0.0)$ (Dracup et al., 1980; McKee et al., 1993).

In addition, drought severity may be calculated as follows

severity $=\sum_{k=m}^{k=n} \operatorname{SLI}_{k}$ 

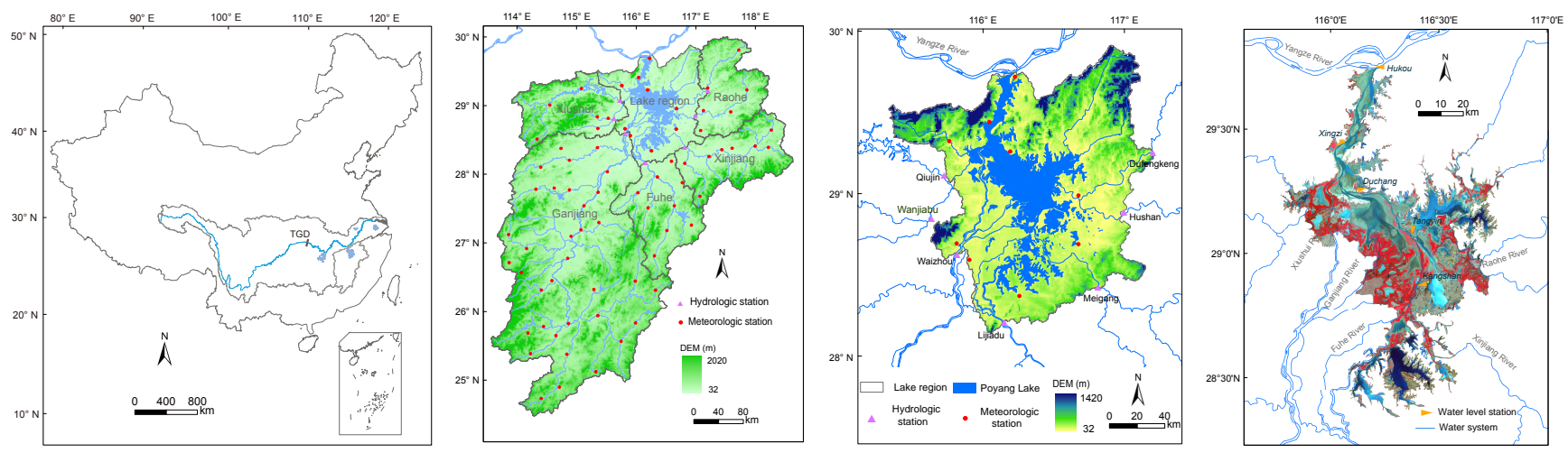

Figure 1. Geographic location of Poyang Lake, China. The lake is principally fed by five river systems of the Poyang Lake basin. Lake water flows into the Yangtze River via a single outlet at the Hukou. Jiujiang is located $25 \mathrm{~km}$ upstream of the Hukou on the Yangtze River. The Three Gorges Dam (TGD) is upstream of the river.

where $m$ denotes the initialization time of a drought and $n$ represents the termination time (Keyantash and Dracup, 2002; Mishra and Singh, 2010). Drought magnitude is then calculated as (Keyantash and Dracup, 2002)

Magnitude $=$ Severity $/$ duration .

\subsection{Contribution of water deficiency to lake droughts}

A lake drought results directly from an abnormal change in the lake water budget. A general water balance for lake in a period can be described as follows

$\Delta_{\mathrm{L}}=P_{\mathrm{L}}-E_{\mathrm{L}}+G_{\mathrm{L}}+I_{\mathrm{L}}-O_{\mathrm{L}}$,

where $\Delta_{\mathrm{L}}$ is the lake water budget or change in lake storage (millimeters or cubic meters, hereafter $\mathrm{mm}$ or $\mathrm{m}^{3}$ ), $P_{\mathrm{L}}$ is precipitation $\left(\mathrm{mm}\right.$ or $\left.\mathrm{m}^{3}\right), E_{\mathrm{L}}$ is lake evaporation $\left(\mathrm{mm}\right.$ or $\left.\mathrm{m}^{3}\right)$, $G_{\mathrm{L}}$ is groundwater net inflow to the lake ( $\mathrm{mm}$ or $\mathrm{m}^{3}$ ), $I_{\mathrm{L}}$ is

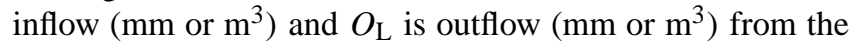
lake.

Once the water budget appears abnormal, it suffers from the anomalies of some or all the water components, namely, low precipitation, high evapotranspiration, low inflow and/or high outflow. At the monthly scale, for a water component $X$, being $\Delta_{\mathrm{L}}, P_{\mathrm{L}}, E_{\mathrm{L}}, G_{\mathrm{L}}, I_{\mathrm{L}}$ or $O_{\mathrm{L}}$, its anomaly is described as follows

$\widetilde{X}_{i j}=X_{i j}-\bar{X}_{j}$,

where $\tilde{X}_{i j}$ denotes the anomaly of the water component (mm or $\mathrm{m}^{3}$ ) for year $i$ and month $j . \bar{X}_{j}$ is the multi-year mean of $X_{i j}$ in month. Notably, Eq. (5) defines an absolute water deficiency from its normal amount, different from Eq. (1) that defines a relative deficiency for drought identification. The equation offers a baseline to quantify contributions from individual water components to a drought.

During a drought event, the anomaly of lake water storage in month $l(m<l \leq n), \widetilde{S}_{l}$, results from the consecutive anomalies of the lake water budget (Seneviratne et al., 2012; Teuling et al., 2013), which can be described as

$\widetilde{S}_{l}=\sum_{k=m}^{k=l} \widetilde{\Delta}_{k}$

The contribution from an individual water component to the water deficiency of the lake water storage is quantifiable with a ratio defined as follows

$C_{X_{l}}=\frac{\sum_{k=m}^{k=l} \widetilde{X}_{k}}{\sum_{k=m}^{k=l} \widetilde{\Delta}_{k}}$,

where $C_{X_{l}}$ denotes the contribution, the numerator is the sum of the monthly anomalies of the water component from month $m$ to $l$. $\sum_{k=m}^{k=l} \widetilde{\Delta}_{k}$ is generally negative, but $\sum_{k=m}^{k=l} \widetilde{X}_{k}$ may vary with hydroclimatic conditions. For example, precipitation deficiency leads to a negative $\sum_{k=m}^{k=l} \widetilde{X}_{k}$ value and produces a positive $C_{X_{l}}$. Low evapotranspiration may lessen water deficiency and generate a negative $C_{X_{l}}$. Therefore, $C_{X_{l}}$ can be either positive or negative.

Notably, Eq. (7) requires all the involved water components to be independent from each other, which is the general case for $P_{\mathrm{L}}, E_{\mathrm{L}}, G_{\mathrm{L}}$ and $I_{\mathrm{L}}$, but not for $O_{\mathrm{L}}$. Given $O_{\mathrm{L}}$ is largely dependent on the sum of $\left(P_{\mathrm{L}}-E_{\mathrm{L}}+G_{\mathrm{L}}+I_{\mathrm{L}}\right)$, its net contribution to the lake water budget can be described with $\Delta_{\mathrm{Lk}}=\left(P_{\mathrm{Lk}}-E_{\mathrm{Lk}}+G_{\mathrm{Lk}}+I_{\mathrm{Lk}}\right)-O_{\mathrm{Lk}}$. The anomaly of the net contribution is $\widetilde{\Delta}_{k}=\left(\widetilde{P}_{k}-\widetilde{E}_{k}+\widetilde{G}_{k}+\widetilde{I}_{k}\right)-\widetilde{O}_{k}$, and it is used to replace $\widetilde{O}_{k}=O_{k}-\bar{O}_{k}$ in Eq. (7) for the quantification of the relative contribution of the outflow.

Equation (7) is useful to quantify hydroclimatological influences on drought, and applicable to any single month in a drought period. However, it may not be meaningful for an 
entire drought, because the storage anomaly will return back to zero at the end of the drought. In contrast, when a drought event reaches its highest storage deficit, it has the highest intensity, the main criterion for drought classification. Therefore, quantification of the hydroclimatological contribution for the month with the highest intensity (lowest SLI) is fundamental to clarify drought causes.

\subsection{Contribution of basin-scale hydroclimatic influences on lake droughts}

In addition to the quantification of water deficiency in inputs and outputs to the lake, it is also important to understand the causes of inflow deficiency for a complete understanding of hydroclimatic influences on lake droughts. Lake inflow originates from precipitation on its contributing basin. Given the water balance for the basin in a period, lake inflow is described as

$I_{\mathrm{L}}=P_{\mathrm{B}}-E_{\mathrm{B}}+\Delta_{\mathrm{B}}$

where $P_{\mathrm{B}}$ is the precipitation $\left(\mathrm{mm}\right.$ or $\left.\mathrm{m}^{3}\right), E_{\mathrm{B}}$ is the evapotranspiration ( $\mathrm{mm}$ or $\mathrm{m}^{3}$ ) and $\Delta_{\mathrm{B}}$ is the change of water storage $\left(\mathrm{mm}\right.$ or $\left.\mathrm{m}^{3}\right)$, including soil moisture and groundwater in the basin.

In practice, there are often areas ungauged downstream from hydrological stations. In this case, the lake inflow includes two parts, one from gauged areas and another from ungauged $\operatorname{areas}\left(I_{\mathrm{L}}=I_{\mathrm{U}}+I_{\mathrm{G}}\right)$ :

$I_{\mathrm{U}}=P_{\mathrm{U}}-E_{\mathrm{U}}+\Delta_{\mathrm{U}}$,

$I_{\mathrm{G}}=P_{\mathrm{G}}-E_{\mathrm{G}}+\Delta_{\mathrm{G}}$,

where the subscript $G$ represents the components for the gauged areas and the subscript $U$ for the ungauged areas.

In combination with Eqs. (4) and (9a), the lake water budget can be expressed as

$\Delta_{\mathrm{L}}=\underbrace{P_{\mathrm{L}}-E_{\mathrm{L}}+G_{\mathrm{L}}}_{\text {lake }}+\underbrace{P_{\mathrm{U}}-E_{\mathrm{U}}+\Delta_{\mathrm{U}}}_{\text {ungauged_area }}+I_{\mathrm{G}}-O_{\mathrm{L}}$.

Or in parallel,

$\Delta_{\mathrm{L}}=\underbrace{P_{\mathrm{R}}-E_{\mathrm{R}}+\Delta_{\mathrm{R}}}_{\text {lake_region }}+I_{\mathrm{G}}-O_{\mathrm{L}}$

where the subscript $R$ represents the components for the lake region. It shows that the lake change involves water budgets in the lake and the ungauged areas, in addition to gauged inflow and outflow.
Further incorporated with Eq. (9b), the lake water budget can be expressed as

$$
\begin{aligned}
\Delta_{\mathrm{L}} & =\underbrace{P_{\mathrm{L}}-E_{\mathrm{L}}+G_{\mathrm{L}}}_{\text {lake }}+\underbrace{P_{\mathrm{U}}-E_{\mathrm{U}}+\Delta_{\mathrm{U}}}_{\text {ungauged_area }} \\
& +\underbrace{P_{\mathrm{G}}-E_{\mathrm{G}}+\Delta_{\mathrm{G}}}_{\text {gauged_area }}-O_{\mathrm{L}} .
\end{aligned}
$$

Or in parallel,

$$
\Delta_{\mathrm{L}}=\underbrace{P_{\mathrm{R}}-E_{\mathrm{R}}+\Delta_{\mathrm{R}}}_{\text {lake_region }}+\underbrace{P_{\mathrm{G}}-E_{\mathrm{G}}+\Delta_{\mathrm{G}}}_{\text {gauged_area }}-O_{\mathrm{L}} .
$$

The water anomaly of each component in Eqs. (10) and (11) can be defined with Eq. (5). Their contributions to the abnormal change of the lake storage (Eq. 6) can be determined for water balance at different spatial scales, namely, the lake, the lake region and the lake basin.

\section{Study area and data processing}

\subsection{Study area and data}

Poyang Lake is located at the northern part of the Poyang Lake basin, a sub-basin of the Yangtze River basin of China (Fig. 1a). The lake has a maximum area of $3860 \mathrm{~km}^{2}$ with an average depth of $8 \mathrm{~m}$ at the lake stage of $22 \mathrm{~m}$ (Shankman et al., 2003). It varies remarkably from several thousand $\mathrm{km}^{2}$ in summer to less than one thousand $\mathrm{km}^{2}$ in winter (Liu et al., 2013). There are five stations (Kangshan, Tangyin, Duchang, Xingzi and Hukou) to measure lake stage across the lake from the south to the north (Fig. 1d). Lake water flows out into the Yangtze River via the Hukou outlet. The lake water principally comes from five major river systems including Xiushui, Ganjiang, Fuhe, Raohe and Xinjiang. Seven hydrological control stations (Qiujin, Wanjiabu, Waizhou, Lijiadu, Meigang, Dufengkeng and Shizhenjie) are located downstream to measure the discharge of the five rivers (Fig. 1b). The lake region (Fig. 1c) downstream from the stations is ungauged, with an area of $23089 \mathrm{~km}^{2}$, approximately 6 times the maximum lake size. The Poyang Lake basin has an area of $162225 \mathrm{~km}^{2}$ and belongs to a humid subtropical climate zone with an annual mean surface air temperature of $17.5^{\circ}$ and a mean annual precipitation of $1640 \mathrm{~mm}$ for the years 1960-2010 (Liu et al., 2012). Forestlands, agricultural fields, grasslands, bare land and water surfaces are the dominant land cover types (Liu et al., 2012).

Daily lake stage data from five hydrological stations and daily discharge data from seven control stations were obtained from the Hydrological Bureau of Poyang Lake. Lake stage data from Xingzi and Hukou were available for the period 1961-2010, but the data from the other three stations were available only until 2008. Daily discharge data for the Hukou outlet are available from the Hydrological Bureau of the Yangtze River Water Resources Commission. 
Daily precipitation data from 73 national weather stations within the Poyang Lake basin are available from the National Meteorological Information Center of China for the period 1961-2010. Regional evapotranspiration estimates were extracted from the latest satellite products (MOD16) of the Moderate resolution Imaging Spectroradiometer (MODIS) (http://www.ntsg.umt.edu/project/mod16) (Mu et al., 2011) for the lake region and the gauged basin in 2000-2010. In addition, the lake stage at Hukou is available for the case without the TGD for the period 2006-2010, which is the output of the CHAM-Yangtze model (Lai et al., 2013).

\subsection{Drought quantification}

To identify lake droughts, SLI was calculated with Eq. (1) from monthly lake stage. Since it is approximately $110 \mathrm{~km}$ from the north to the south of Poyang Lake, a representative gauge was sought. Among five stations to measure the lake stage, the SLI values of Xingzi station had the highest correlation with that calculated from averaged lake stage of the five stations using all the available data for the period 1960-2008 ( $\left.y=0.9953 x, R^{2}=0.9901, p<0.0001\right)$. Thus, the Xingzi station was selected for drought quantification.

Prior to drought quantification with SLI, the monthly lake stage was evaluated for its fit with the gamma distribution in each calendar month (McKee et al., 1993). The statistical evaluation demonstrated the goodness-of-fit at a significant level of $1 \%$ with the Kolmogorov-Smirnov test (LloydHughes and Saunders, 2002) for all 12 months (Fig. 2). Subsequently, drought initialization, termination, duration, intensity, severity and frequency were determined from the SLI values of Xingzi, with the criteria described in Sect. 2.1. Finally, all the lake droughts were identified and classified into extreme, severe or moderate drought (McKee et al., 1993).

In addition, for the case without the TGD impoundments, the lake stage at Xingzi was estimated from its highly correlated relationship with Hukou, $y=0.9594 x+0.8034$ $\left(R^{2}=0.9949\right)$ (Min and Zhan, 2013), for the period 20062010. Consequently, the SLI values of Xingzi were recalculated for the case without TGD. This serves as a reference to evaluate the TGD effect on the lake droughts.

\subsection{Water budget analysis}

To quantify hydroclimatic influences on lake droughts, the water budget analysis was designed at multi-spatial scales: the lake, lake region and gauged basin (Fig. 1). At the lake scale, water components include precipitation, evaporation, groundwater net inflow, inflows from gauged and ungauaged areas, and outflow (Eq. 4). It has been difficult to perform water balance analysis with a high accuracy for the lake. First, evaporation data are unavailable for the lake in monthly time series. Second, the lake inundation area shows remarkable variation, which significantly regulates wetland evapotranspiration (Zhao and Liu, 2014). Third, there are many small rivers and brooks downstream from the hydrological control stations. It is impractical to measure all of the surface runoff into Poyang Lake. Given the hydrological data, the Poyang Lake region is thus the minimum closure entity directly available for the water budget analysis. Furthermore, for complete understanding of climatic, hydrologic and anthropogenic influences on lake droughts, water budget analysis should be performed for the lake basin, with a focus on the causes of inflow deficiency. Besides, the boundary effect of the Yangtze River is taken into consideration to account for the anomaly of lake outflow.

Specification of normal hydrologic conditions is a prerequisite for determining water deficiency. First, precipitation data were grouped for the Poyang lake region and the gauged basin. Multi-year means of monthly precipitation were obtained from the observation data for the period 1961-2010. Second, multi-year means of monthly discharge were calculated from the data for inflows and outflow in the period. Third, since evapotranspiration data prior to 2000 were unavailable, the annual evapotranspiration was calculated from the difference between annual precipitation and discharge, respectively, for the lake region and the gauged basin in 1961-2010. The multi-year mean of monthly evapotranspiration was then obtained by distributing the annual value with a monthly weighting factor calculated from the MOD16 time series, with an assumption that the seasonal variation is relatively similar for the period 1961-2010.

Once the normal hydrologic condition was established, the water deficiency of a water component (Eq. 5) and its contribution to the lake drought were determined (Eq. 7). It was applied to the water budget for the lake region (Eq. 10b) and the gauged basin (Eq. 11b), respectively. For the basin, a 1-month lag was determined with correlation analysis between peak rainfall and peak discharge, and it was applied to account for the peak difference (Senay et al., 2011; Liu et al., 2013). In addition, there are three points addressed here. First, $\Delta_{\mathrm{R}}$ in Eq. (10b) for the lake region is only $1.3 \%$ of the total water balance and is neglected in the present study (Wan and $\mathrm{Xu}, 2010$; Zhang et al., 2014). Second, $\Delta_{\mathrm{G}}$ in Eq. (9b) for the gauged basin is generally unavailable. According to Feng and Liu (2014), it is roughly $5 \%$ of the total water balance and is neglected here. Third, while the MOD16 data sets have been extensively evaluated and applied worldwide, e.g., in Australia, Brazil, Asia and the United States (Loarie et al., 2011; Kim et al., 2012; Velpuri et al., 2013; Wang et al., 2014), our recent assessment showed that it had an error of approximately $10 \%$ for the study area (Wu et al., 2013). This error, together with the neglected $\Delta_{\mathrm{R}}$ and $\Delta_{\mathrm{G}}$, may introduce uncertainties. Given that the water anomaly (Eq. 5) and relative contribution (Eq. 7) are used, the uncertainties would not be enlarged but minimized in water balance calculation and water budget analysis.

It should be emphasized that, for the sake of addressing water contribution at the lake region and the gauged basin, the water amounts (unit in $\mathrm{m}^{3}$ ) of all the water components 

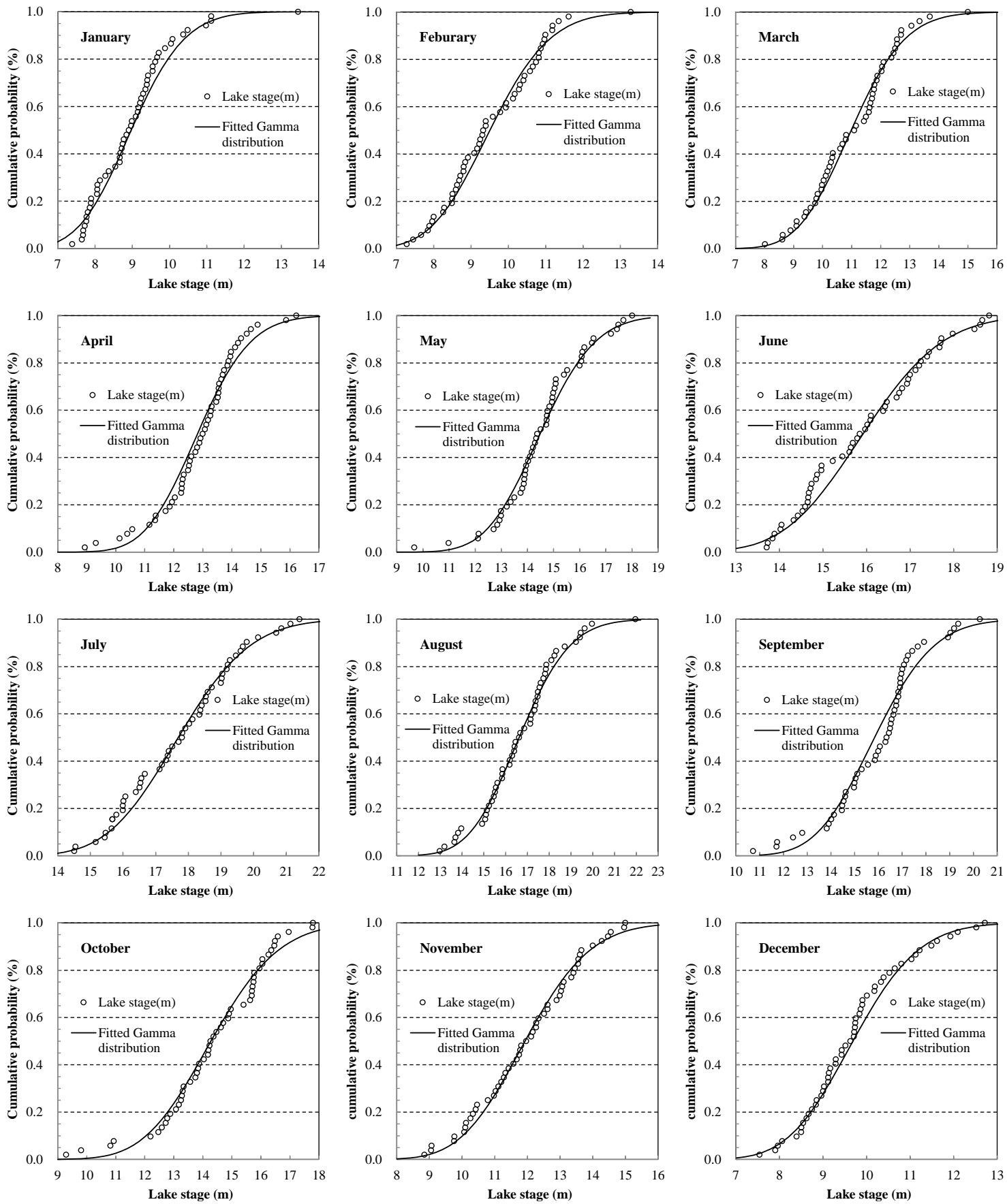

Figure 2. Statistical distribution of monthly average lake stages with a fitted gamma distribution for each calendar month at Xingzi of Poyang Lake in 1961-2010.

were normalized to equivalent water height (unit in $\mathrm{mm}$ ) of the whole basin (unit in $\mathrm{km}^{2}$ ). Besides, statistical approaches were adopted in the present analysis (Lomax, 2001), in which paired $F$ test (and $t$ test) were used to examine the variance (and mean) difference between the statistics for the period 1961-2000 and that for the period 2001-2010.

\section{Results and discussion}

\subsection{Poyang Lake droughts in the past decade}

Figure 3a illustrates the SLI variation for Poyang Lake in the past decade. Negative values prevail over positive values, indicating the dry phase dominates the lake for the period. Three extreme, two severe and four moderate droughts, ac- 
(a)

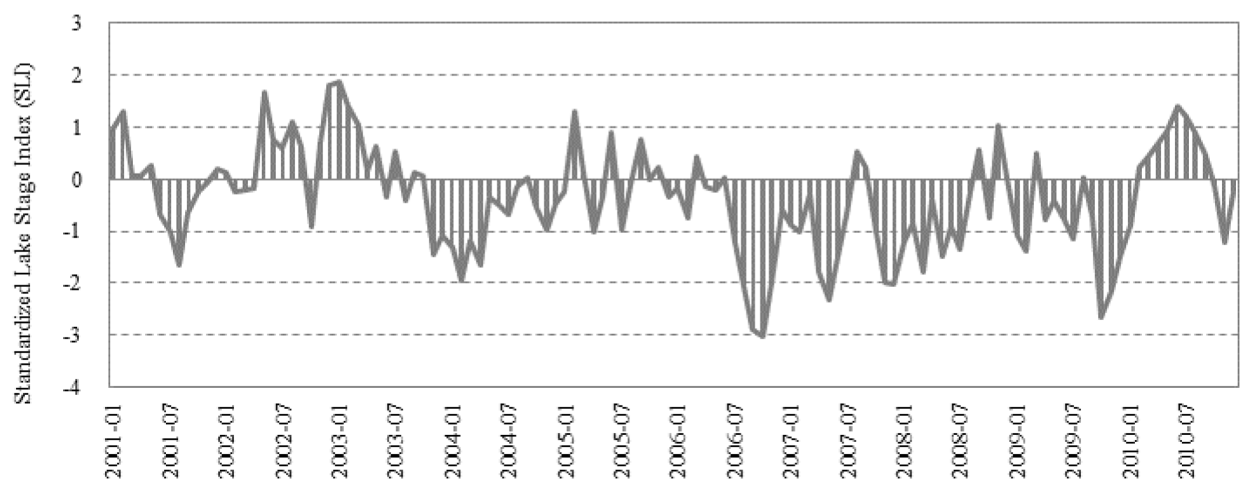

(b)

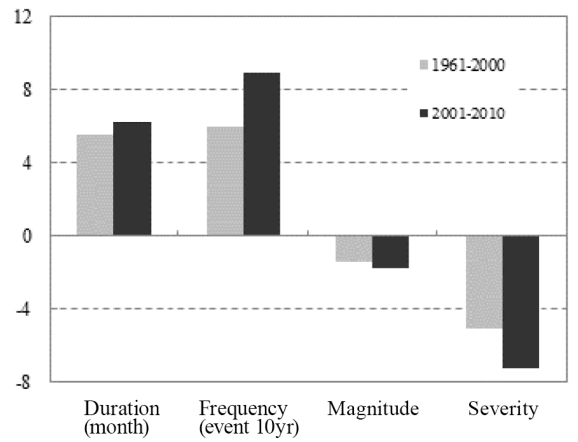

(c)

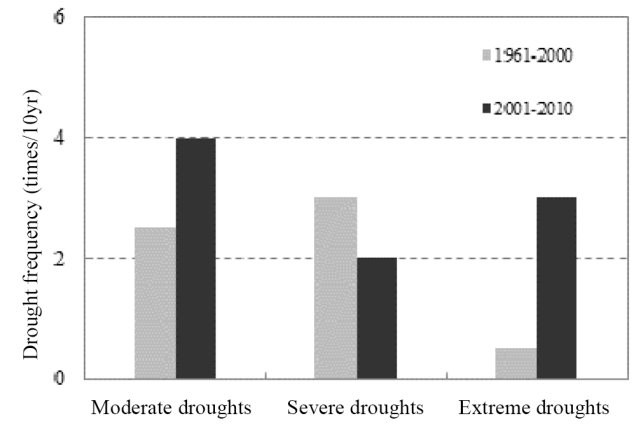

Figure 3. Poyang Lake droughts in 2001-2010. (a) Variation in the standardized lake stage index (SLI). (b) Drought duration, frequency, intensity and severity, and (c) Drought frequency for moderate, severe and extreme droughts, compared to 1961-2000.

Table 1. Drought events occurring during the 2001-2010 time period.

\begin{tabular}{llrrrl}
\hline No. & Period & $\begin{array}{r}\text { Duration } \\
\text { (month) }\end{array}$ & $\begin{array}{r}\text { Intensity } \\
\text { (probability) }\end{array}$ & Severity & $\begin{array}{l}\text { Drought } \\
\text { classification }\end{array}$ \\
\hline 1 & Jun 2001-Nov 2001 & 6 & $-1.64(0.0505)$ & -4.33 & severe \\
2 & Nov 2003-Aug 2004 & 10 & $-1.96(0.0250)$ & -10.23 & severe \\
3 & Apr 2005-May 2005 & 2 & $-1.03(0.1515)$ & -1.39 & moderate \\
4 & Jul 2006-Jul 2007 & 13 & $-3.03(0.0012)$ & -20.22 & extreme \\
5 & Oct 2007-Aug 2008 & 11 & $-2.01(0.0222)$ & -13.21 & extreme \\
6 & Jan 2009-Feb 2009 & 2 & $-1.39(0.0823)$ & -2.47 & moderate \\
7 & Apr 2009-Jul 2009 & 4 & $-1.14(0.1271)$ & -3.11 & moderate \\
8 & Sep 2009-Jan 2010 & 5 & $-2.66(0.0039)$ & -7.90 & extreme \\
9 & Oct 2010-Dec 2010 & 3 & $-1.21(0.1131)$ & -1.56 & moderate \\
\hline Totals & & $7.3 \pm 3.8$ & $-1.79 \pm 0.70$ & $-7.16 \pm 6.41$ & \\
\hline
\end{tabular}

cording to the drought classification criteria (McKee et al., 1993), occurred in this period. Among the nine cases, three droughts started in spring, two in summer and four in autumn (Table 1). Drought duration varied from 2 to 13 months with a mean of 7.3 months and a standard deviation (SD) of 3.8 months, which demonstrated that the lake droughts could occur in any month. Drought intensity ranged from -1.03 to -3.03 with a mean of $-1.79 \pm 0.70$. The top three lowest SLI values were $-3.03,-2.66$ and -2.01 , corresponding to probabilities of $0.12,0.39$ and $2.22 \%$, respectively, for each occurrence. Drought severity varied from -1.39 to -20.22 with a mean of $-7.16 \pm 6.41$. More specifically, in the category of extreme drought, the drought event that ranked first in both intensity and severity occurred from July 2006 to July 2007, lasting 13 months. The 2006 drought was addressed in Feng et al. (2012) and Wu and Liu (2014) in terms of inundated area, whereas the present study quantified its probability of occurrence and revealed that the drought lasted longer 
than the previous reports. The second most severe drought event emerged in September 2009-January 2010, persisting 5 months. The third most severe drought took place from October 2007 to August 2008, lasting 11 months. The two droughts in the severe drought category spanned 6 and 10 months, respectively. The four droughts in the moderate drought category lasted 2-4 months. It appears that a drought with a lower SLI is usually more severe and lasts for a longer time.

In comparison to the years 1961-2000, the lake droughts changed in terms of duration, frequency, intensity and severity in the past decade (Fig. 3b). On average, drought duration extended from 5.6 to 6.2 months. Drought frequency increased from 6.0 to 9.0 events per decade. Drought intensity intensified from -1.38 to -1.79 and drought severity increased from -5.02 to -7.16 . With regard to the intensification, further analysis revealed that the moderate drought events increased, severe droughts decreased, but the extreme droughts increased from 0.5 to 3.0 events per decade (Fig. 3c). Overall, the lake droughts have worsened in terms of duration, frequency, intensity and severity over the last decade.

\subsection{Hydroclimatic change at Poyang Lake region}

Normal variation of water components is a baseline for the quantitative analysis of drought occurrence as an abnormal change. Figure 4a shows the multi-year mean of monthly precipitation $\left(P_{\mathrm{R}}\right)$ and evapotranspiration $\left(E_{\mathrm{R}}\right)$ for the lake region, lake inflow $(I)$ from five major rivers and outflow $(O)$ into the Yangtze River. The monthly precipitation varied with a peak in June followed by a sharp decrease. Inflow had a similar seasonal pattern. Outflow had the maximum value in June and the minimum in January. Maximum evapotranspiration appeared in August and the minimum in December. From a perspective of water balance, the water budget was positive from January to June with a peak in June. It became negative from July to December, and the minimum value appeared in October. These results indicate a shift in water budget from a surplus phase in the first half of the year to a deficit phase in the second half of the year. The deficit phase is a part of the normal hydrologic condition, and thus it does not necessarily mean a drought occurrence. Furthermore, in the annual water budget, the equivalent water supply from local precipitation was $312.0 \mathrm{~mm}$, and that from inflow was $714.4 \mathrm{~mm}$, more than 2 times that of the local precipitation. The water loss from local evapotranspiration was $118.3 \mathrm{~mm}$, and that from outflow was $908.1 \mathrm{~mm}$, approximately 7.7 times that of the local evapotranspiration. The fact that the inflow and outflow were much higher than local precipitation and evapotranspiration implies the dominant role of hydrologic components over meteorological components in regulating Poyang Lake within the lake region.

Lake droughts occur when abnormal change appears in the water budget. Table 2 lists the water components for the lake (a)

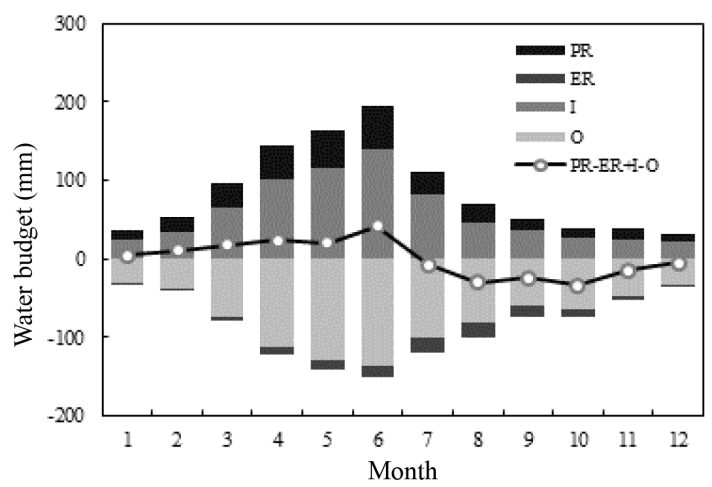

(b)

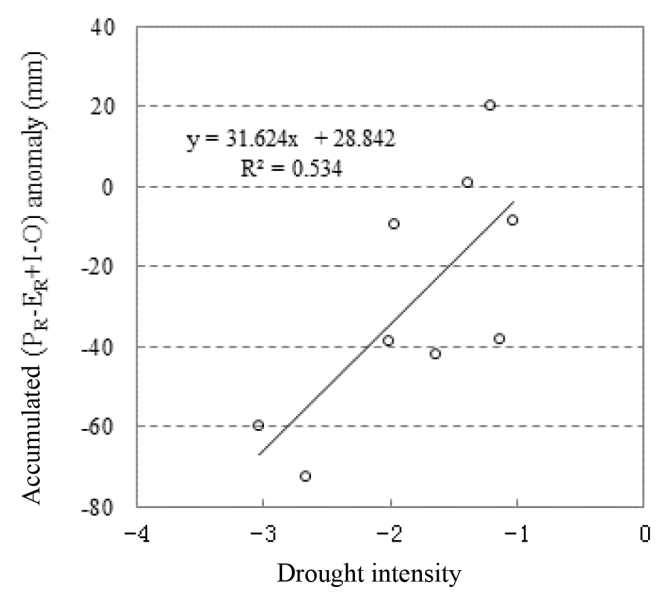

Figure 4. (a) Multi-year mean of monthly precipitation $\left(P_{\mathrm{R}}\right)$ and evapotranspiration $\left(E_{\mathrm{R}}\right)$ for the Poyang Lake region, lake inflow ( $I$ ) from five major rivers of the Poyang Lake basin, and outflow $(O)$ into the Yangtze River. All the water amounts are normalized to equivalent water height of the whole Poyang Lake basin. (b) The relationship between drought intensity and accumulated anomaly of $\left(P_{\mathrm{R}}-E_{\mathrm{R}}+I\right)$ of each event for nine cases of Poyang Lake droughts.

region during the periods of lake droughts. The water budgets $\left(P_{\mathrm{R}}-E_{\mathrm{R}}+I-O\right)$ were $-67.1,-12.6$ and $-69.3 \mathrm{~mm}$ for three extreme lake droughts, -71.6 and $27.7 \mathrm{~mm}$ for two severe lake droughts and 72.0, 5.4, 18.5 and $-66.1 \mathrm{~mm}$ for four moderate lake droughts. In sum, the budget was negative (deficit) for five cases and positive (surplus) for four cases. Despite the positive water budgets, the large negative anomalies of $P_{\mathrm{R}}-E_{\mathrm{R}}+I$ for the cases illustrated that the lake water income $\left(P_{\mathrm{R}}-E_{\mathrm{R}}+I\right)$ was exceptionally lower than normal. The low water income resulted from largely decreased inflow and precipitation, as well as increased evapotranspiration. The positive water budgets were attributed to the water surplus period in the first half of the year. In this sense, the definition of drought is a water anomaly referenced to a normal state of either water surplus or deficit phase. It indicated 
Table 2. Water components (unit in $\mathrm{mm}$ ) of the Poyang Lake region and of the gauged basin for the drought periods. The values in parenthesis are the anomaly of a component against the multi-year mean in 1961-2010. All the water amounts are normalized to equivalent water height of the whole Poyang Lake basin.

\begin{tabular}{|c|c|c|c|c|c|c|c|c|c|c|}
\hline & \multicolumn{6}{|c|}{ Lake region } & \multicolumn{4}{|c|}{ Gauged basin } \\
\hline & $P_{\mathrm{R}}$ & $E_{\mathrm{R}}$ & $I$ & $O$ & $P_{\mathrm{R}}-E_{\mathrm{R}}+I$ & $P_{\mathrm{R}}-E_{\mathrm{R}}+I-O$ & $P_{\mathrm{G}}$ & $E_{\mathrm{G}}$ & $P_{\mathrm{G}}-E_{\mathrm{G}}$ & $P_{\mathrm{G}}-E_{\mathrm{G}}-O$ \\
\hline \multirow[t]{2}{*}{ Jun 2001-Nov 2001} & 133.6 & 106.6 & 333.9 & 432.5 & 360.9 & -71.6 & 755.9 & 575.3 & 180.6 & -251.9 \\
\hline & $(-15.9)$ & $(24.8)$ & $(-19.6)$ & $(-58.5)$ & $(-60.2)$ & $(-1.7)$ & $(-23.3)$ & $(55.1)$ & $(-78.4)$ & $(-19.9)$ \\
\hline \multirow[t]{2}{*}{ Nov 2003-Aug 2004} & 246.0 & 122.1 & 367.0 & 463.2 & 490.9 & 27.7 & 1282.4 & 666.7 & 615.7 & 152.5 \\
\hline & $(-39.9)$ & (28.1) & $(-284.2)$ & $(-320.5)$ & $(-352.2)$ & $(-31.7)$ & $(-210.3)$ & (85.1) & $(-295.4)$ & (24.7) \\
\hline \multirow[t]{2}{*}{ Apr 2005-May 2005} & 81.2 & 31.2 & 225.2 & 203.3 & 275.2 & 72.0 & 489.5 & 149.9 & 339.6 & 136.3 \\
\hline & $(-8.3)$ & (9.1) & $(6.9)$ & $(-39.1)$ & $(-10.4)$ & $(28.7)$ & (19.3) & (14.6) & (4.7) & (43.8) \\
\hline \multirow[t]{2}{*}{ Jul 2006-Jul 2007} & 241.9 & 182.0 & 584.3 & 711.3 & 644.2 & -67.1 & 1469.4 & 1010.3 & 459.1 & -252.2 \\
\hline & $(-100.9)$ & (44.8) & $(-210.7)$ & $(-296.3)$ & $(-356.4)$ & $(-60.1)$ & $(-321.2)$ & (152.1) & $(-473.3)$ & $(-177.0)$ \\
\hline \multirow[t]{2}{*}{ Oct 2007-Aug 2008} & 258.6 & 134.3 & 536.3 & 673.1 & 660.6 & -12.6 & 1312.0 & 717.1 & 594.9 & -78.2 \\
\hline & $(-39.0)$ & (31.6) & $(-141.9)$ & $(-175.1)$ & $(-212.5)$ & $(-37.4)$ & $(-248.0)$ & $(72.5)$ & $(-320.5)$ & $(-146.6)$ \\
\hline \multirow[t]{2}{*}{ Jan 2009-Feb 2009} & 24.1 & 7.7 & 26.3 & 37.3 & 42.7 & 5.4 & 101.4 & 42.8 & 58.6 & 21.3 \\
\hline & $(-8.2)$ & (1.2) & $(-30.1)$ & $(-30.1)$ & $(-39.5)$ & $(-9.4)$ & $(-74.7)$ & (4.9) & $(-79.6)$ & $(-49.5)$ \\
\hline \multirow[t]{2}{*}{ Apr 2009-Jul 2009} & 129.9 & 72.5 & 268.1 & 307.0 & 325.5 & 18.5 & 698.8 & 401.2 & 297.6 & -9.4 \\
\hline & $(-44.9)$ & (16.3) & $(-169.9)$ & $(-171.8)$ & $(-231.1)$ & $(-59.3)$ & $(-194.4)$ & (51.8) & $(-246.1)$ & $(-74.3)$ \\
\hline \multirow[t]{2}{*}{ Sep 2009-Jan 2010} & 49.9 & 45.1 & 93.4 & 167.5 & 98.2 & -69.3 & 328.2 & 256.5 & 71.7 & -95.8 \\
\hline & $(-12.0)$ & (11.2) & $(-39.6)$ & $(-68.6)$ & $(-62.8)$ & (5.8) & $(-11.8)$ & (35.4) & $(-47.2)$ & (21.4) \\
\hline \multirow[t]{2}{*}{ Oct 2010-Dec 2010} & 46.0 & 20.9 & 79.7 & 170.9 & 104.8 & -66.1 & 228.9 & 123.1 & 105.8 & -65.1 \\
\hline & $(12.0)$ & (15.5) & $(6.0)$ & $(24.2)$ & $(12.6)$ & $(-11.6)$ & (48.6) & (13.4) & $(35.1)$ & (10.9) \\
\hline \multirow[t]{2}{*}{ Totals } & 1211.1 & 722.3 & 2514.2 & 3166.1 & 3003.0 & -163.1 & 6666.4 & 3942.9 & 2723.5 & -442.5 \\
\hline & $(-257.1)$ & (172.5) & $(-883.1)$ & $(-1135.9)$ & $(-1312.5)$ & $(-176.7)$ & $(-1016.0)$ & (484.8) & $(-1500.8)$ & $(-366.5)$ \\
\hline
\end{tabular}

that a drought occurrence was more closely related to the water deficiency (negative anomaly) of water budget than the net water budget. For example, the net water budget did not show statistically significant relationships with drought intensity. On the contrary, the total water anomaly of a drought event showed a significant relationship with drought intensity $(x)\left(y=31.624 x+28.842, n=9, R^{2}=0.534, p<0.05\right)$ (Fig. 4b). In general, the water budget analysis highlighted the importance of water deficiency in reference to a normal condition of either water surplus or deficit.

Drought causes can be traced from the relative contribution of individual water components. Table 3 shows the ratios of the total water anomaly of a component to that of the water budget up the time of peak drought (maximum intensity) for each event (Eq. 7). In the lake region, the ratio for inflow is largest for most cases, followed by $O, P_{\mathrm{R}}$ and $E_{\mathrm{R}}$, indicating the dominant role of inflow in drought formation. Meanwhile, hydroclimatological contributions to each individual drought varied greatly between droughts. For example, $O$ was larger than $P_{\mathrm{R}}$ for June 2001-November 2001, and lower for September 2009-January 2010. In addition to the positive contribution, a water component may contribute negatively. For example, one negative value appeared for inflow (Table 3), which was attributable to the normal inputs $\left(I+P_{\mathrm{R}}-E_{\mathrm{R}}\right)$ accompanied by excessive $O$ for July 2006October 2006. Since inflow reduction is the major contribution to drought formation in the lake region, it is vital to trace how precipitation and evapotranspiration have changed at the basin scale.

\subsection{Hydroclimatic change at Poyang Lake basin}

Likewise, prior to performing a water budget analysis, it is necessary to clarify the normal hydrologic condition. Generally, precipitation $\left(P_{\mathrm{G}}\right)$ and evapotranspiration $\left(E_{\mathrm{G}}\right)$ had similar seasonal patterns in the gauged basin as its counterpart in the lake region (Fig. 5a). Monthly precipitation varied seasonably with a peak in June, followed by peaks in May and April. Major precipitation appeared in the first half of the year. Monthly evapotranspiration was generally less than precipitation and its top three highest values appeared from June-August. Monthly outflow was approximately half of the precipitation with a similar seasonal pattern. Consequently, the monthly water budget was positive (surplus) from December to June and negative (deficit) from July to November. The highest water surpluses appeared in March, April and May, and the lowest water deficits in July, August and September. On an annual scale, runoff was approximately $55 \%$ of precipitation, $10 \%$ higher than evapotranspiration, which is one of the climate features of this humid subtropical region.

The water budget was $-252.2,-79.4$ and $-95.8 \mathrm{~mm}$ for the three extreme droughts, -251.9 and $152.0 \mathrm{~mm}$ for the two severe droughts, and 136.3, 21.3, -9.5 and $-65.1 \mathrm{~mm}$ for the moderate droughts (Table 2). For six negative cases, the water budget featured less precipitation (negative anomaly) and more evapotranspiration (positive anomaly). For three positive cases, $P_{\mathrm{G}}-E_{\mathrm{G}}$ had large negative anomalies over $100 \mathrm{~mm}$, but the water budgets became positive due to the largely reduced outflow. For the three extreme droughts, $P_{\mathrm{G}}-E_{\mathrm{G}}$ was much lower than the normal, sug- 
Table 3. Contribution of each water component (unit in $100 \%$ ) to the total water anomaly up the time of peak drought (highest drought intensity) for the lake region and gauged basin.

\begin{tabular}{lrrrrrr}
\hline Lake droughts & \multicolumn{4}{c}{ Lake region } & \multicolumn{3}{c}{ Gauged basin to $I$} \\
\cline { 2 - 7 } & $P_{\mathrm{R}}$ & $E_{\mathrm{R}}$ & $I$ & $O$ & $P_{\mathrm{G}}$ & $E_{\mathrm{G}}$ \\
\hline Jun 2001-Nov 2001 & 0.23 & 0.13 & 0.20 & 0.44 & 0.61 & 0.39 \\
Nov 2003-Aug 2004 & 0.12 & 0.04 & 0.59 & 0.25 & 0.84 & 0.16 \\
Apr 2005-May 2005 & 0.19 & 0.03 & 0.41 & 0.38 & 0.98 & 0.02 \\
Jul 2006-Jul 2007 & 0.68 & 0.57 & -1.25 & 0.99 & 1.12 & -0.12 \\
Oct 2007-Aug 2008 & 0.25 & 0.14 & 0.32 & 0.29 & 0.75 & 0.25 \\
Jan 2009-Feb 2009 & 0.17 & 0.03 & 0.41 & 0.40 & 0.93 & 0.07 \\
Apr 2009-Jul 2009 & 0.11 & 0.07 & 0.60 & 0.22 & 0.73 & 0.27 \\
Sep 2009-Jan 2010 & 0.34 & 0.14 & 0.36 & 0.16 & 0.73 & 0.27 \\
Sep 2010-Dec 2010 & 0.01 & 0.13 & 0.24 & 0.62 & 0.56 & 0.44 \\
\hline
\end{tabular}

(a)

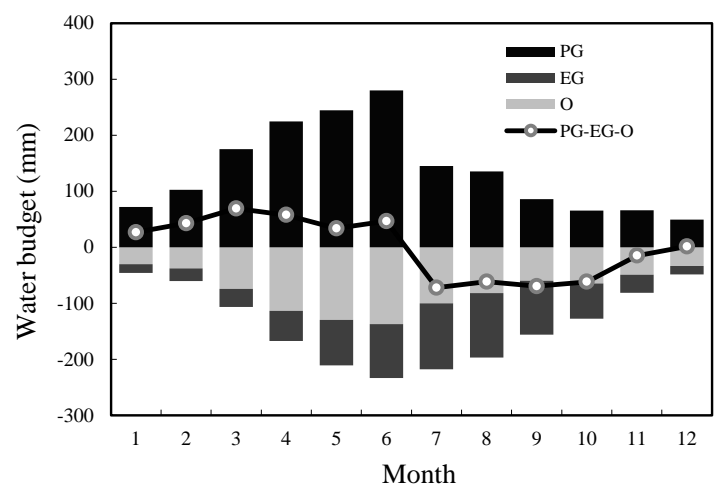

(b)

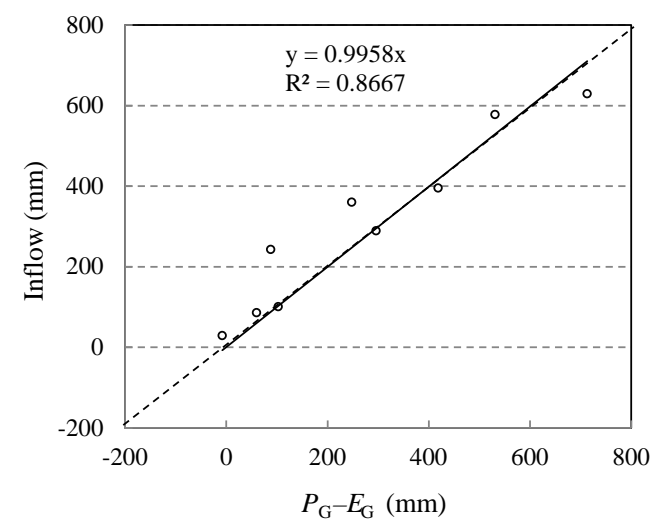

Figure 5. (a) Multi-year mean of monthly precipitation $\left(P_{\mathrm{G}}\right)$ and evapotranspiration $\left(E_{\mathrm{G}}\right)$ for the Poyang Lake basin, and outflow $(O)$ into the Yangtze River. (b) The relationship between $P_{\mathrm{G}}-E_{\mathrm{G}}$ and inflow for nine cases of Poyang Lake droughts. All the water amounts are normalized to equivalent water height of the whole Poyang Lake basin. gesting that meteorological droughts have made significant effects on the drought formation. For all the cases, the water anomalies of $P_{\mathrm{G}}$ and $P_{\mathrm{G}}-E_{\mathrm{G}}$ had positive relationships with drought severity, which was consistent with the water budget for the lake region. Nevertheless, the basin-scale precipitation is the most important water source to the lake, as confirmed by a correlation between $P_{\mathrm{G}}-E_{\mathrm{G}}(x)$ and $I$ (y) $\left(y=0.9958 x, R^{2}=0.8667, n=10, p<0.005\right)$ (Fig. 5b). The $P_{\mathrm{G}}-E_{\mathrm{G}}$-to- $I$ difference was $-28.3 \mathrm{~mm}$, approximately $10 \%$ of $I$, in agreement with our previous study (Wu et al., 2013). The high correlation and relatively small difference also confirmed the suitability of the satellite evapotranspiration data for the study area.

While the inflow reduction resulted from combined hydroclimatic change, precipitation and evapotranspiration may have made different contributions to the drought formation. Table 3 shows that the relative contribution for $P_{\mathrm{G}}$ varied from 0.56 to 1.12 , suggesting that precipitation deficiency is the main driver to reduce the lake inflows during the drought development. Alternatively, the contribution for $E_{\mathrm{G}}$ ranged from -0.12 to 0.44 , highlighting the importance of evapotranspiration in amplifying droughts, in agreement with the conclusion that reduced precipitation can coincide with increased evaporation (Teuling et al., 2013).

\subsection{Mechanisms accounting for recent lake droughts}

The above sections detail the lake droughts as abnormal phenomena and the hydroclimatic contribution to individual drought events. Yet, it remains unclear why the droughts strengthened in the past decade, and whether the droughts resulted from a long-term change of hydroclimatic influences or a seasonal combination of these influences.

Figure 6a shows the accumulated anomalies of the water budget from 2001 to 2010 . At the lake region, the water budget $\left(P_{\mathrm{R}}-E_{\mathrm{R}}+I-O\right)$ declined from mid-2002 to a low value in September 2009, and then increased yet remained in a negative phase. Obviously, the decrease in the water budget is a hydroclimatic setting for the recent drought increase. 
(a)

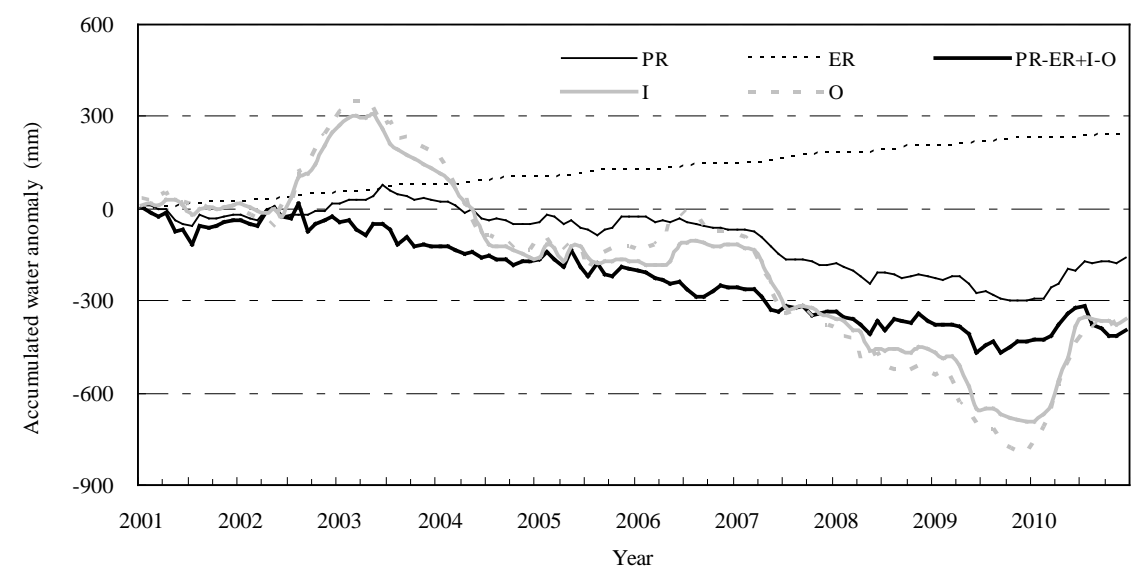

(b)

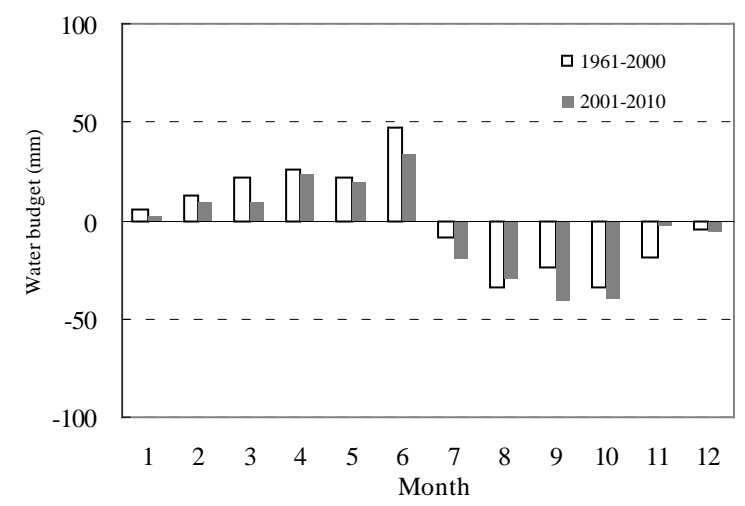

Figure 6. (a) Accumulated anomaly of water components and (b) water budget at the Poyang Lake region for period 2001-2010 compared to 1961-2000. All the water amounts are normalized to equivalent water height of the whole Poyang Lake basin.

The water deficits involve local precipitation and evapotranspiration, lake inflow and outflow, but each of these components has different courses. The accumulated $P_{\mathrm{R}}$ showed a decreasing trend after mid-2003. The accumulated $E_{\mathrm{R}}$ increased gradually but steadily, which was consistent with the rapid increase of surface temperature in the Poyang Lake basin since 1998 (Liu et al., 2012). The $E_{\mathrm{R}}$ exceeded the $P_{\mathrm{R}}$ after April 2010, exhibiting an increasing effect on the water budget. Comparatively, the accumulated $I$ or $O$ had a relatively large variation, consistent with their dominance over $P_{\mathrm{R}}$ and $E_{\mathrm{R}}$ at seasonal scale. They displayed a similar behavior with a peak in spring 2003, and then declined by the end of 2009. In the entire period, precipitation decreased by $5 \%$, evapotranspiration increased by $19 \%$, inflow declined by $5 \%$ and outflow declined by $4 \%$, accounting for the negative water budget in the lake region.

Figure $6 \mathrm{~b}$ displays seasonal variation of the water budget during 2001-2010. In comparison to 1961-2000, the water surplus reduced for the first half of the year, and the water deficit enhanced for the second half of the year except for
August and November. The large reduced surplus includes March and June, and the enhanced deficit includes July and September. The reduced surplus and the enhanced deficit would increase the possibility of drought occurrence and intensify the drought intensity. In the enlarged water deficit, the $P_{\mathrm{R}}-E_{\mathrm{R}}$ and the $I-O$ contributed to 43 and $57 \%$, respectively. In the $I-O$ deficit, inflow decreased but outflow increased. Usually, the outflow decreases with reduced inflow and $P_{\mathrm{R}}-E_{\mathrm{R}}$. Since the Yangtze River serves as a boundary condition of Poyang Lake, the increased outflow is generally a result of weakened blocking effects of the lake-river interactions (Guo et al., 2012; Zhang et al., 2012; Lai et al., 2014).

The weakened effects involve climate change in the upper reaches of the Yangtze River, and water impoundments of the TGD (Guo et al. 2012). Routinely, the TGD impoundment begins in mid-September and spans 1 to 2 months. Among all the drought events, none occurred during exactly the same time span. Accordingly, the TGD impoundments should not be responsible for the increased drought events. However, the 
impoundments lowered the lake stage at the Hukou outlet by 1-2 $\mathrm{m}$ for September-October (Guo et al. 2012; Zhang et al., 2012, 2014). Our analysis indicated that the impoundments led to a change in SLI from -2.70 to -3.03 for the extreme drought in July 2006-July 2007, and from -1.81 to -2.66 for the extreme drought in September 2009-January 2010. The change has two implications. First, the droughts were intensified with the TGD impoundments. Second, a severe drought $(-2.0<\mathrm{LI} \leq-1.5)$ was intensified to an extreme drought $(-\infty<\mathrm{SLI} \leq-2.0)$, which changed the frequency of classified droughts. This is a reasonable explanation for the decrease in the number of severe droughts but increase in extreme droughts (Fig. 3c). Furthermore, according to the latest lake storage curve described in Tan et al. (2013), the lowered lake stages would result in a water loss of $7.1 \times 10^{8}$ and $24.1 \times 10^{8} \mathrm{~m}^{3}$ for each event, respectively. The losses occupied approximately 11.3 and $24.1 \%$ of the total anomalies of outflow at the time of peak drought, corresponding to 11.3 and $3.7 \%$ of the contribution for each drought. In comparison with the hydroclimatic influences, the TGD contribution is limited.

In general, the recently increased droughts were principally attributed to decreased inflow, increased outflow, and reduced local precipitation and increased evapotranspiration at the lake region. First, use of satellite-retrieved evapotranspiration data makes it possible to analyze drought causes from a perspective of water budget with independent measures of major water components. Given that measurement errors are quality controlled, the independent observations are more faithful than model simulations that are susceptible to model uncertainty and empirical parameterization. Indeed, the MOD16 products have been used effectively in water balance studies in the past. Second, in addition to drought quantification, absolute deficiency was defined for water components and water budget in reference to the normal hydrologic state. Individual hydroclimatic contributions were isolated from the total anomalies of the water budget, and the drought causation structure was subsequently distinguished. The quantification approach is straightforward and applicable to separate hydroclimatic influences on droughts, a key issue identified for developing integrated theories of droughts (Kallis, 2008). Third, it is the first time that all the drought events and their causation structure in Poyang Lake were quantified. Most existing studies did not explicitly quantify the droughts but focused on low water levels mainly in autumn seasons. A few studies addressed oneto-two extreme droughts with statistical regression analysis (Feng et al., 2012; Wu and Liu, 2014), without a systematic water balance analysis of the droughts and their statistics in the past decade. The present study completed drought quantification, water budget analysis, isolation of hydroclimatic contributions and clarification of causation structure for the recently increased droughts in Poyang Lake. The results demonstrated that the droughts were due to hydroclimatic factors, with a less important contribution from the
TGD influences. Yet, it should be noted that the present study did not address some potential influences, for example, land cover/use change, agricultural water use, soil moisture variation and vegetation dynamics. These factors may affect the hydrological processes at seasonal and annual scales, and subsequently affect lake stage and droughts, which should be taken into consideration in future studies.

\section{Conclusions}

This paper used standardized lake stage to identify and quantify droughts on the case of Poyang Lake in China. From a perspective of water budget, it defined an absolute deficiency of the water components and water budget in reference to normal hydrologic conditions to determine hydroclimatic contributions to drought formation. Given 5 decades of hydroclimatic observations and latest satellite products, the water budget analysis was performed in the study area.

Our analyses demonstrated that the lake droughts had strengthened in the past decade, in terms of duration, frequency, intensity and severity. The overall contribution to the lake droughts came from decreased inflow, increased outflow, and reduced precipitation and increased evapotranspiration at the lake region. The decreased inflow resulted mainly from lower basin-scale precipitation and less from increases in evapotranspiration. The TGD impoundments were not responsible for the increased drought events, but they did intensify the droughts and change the frequency of classified droughts. Overall, the TGD contribution was limited, compared with the hydroclimatic influences.

The findings of this study provide an example of intensified lake droughts, and offer an insightful view into the droughts under the hydroclimatic and anthropogenic influences. The methodology proposed for quantification of lake droughts and isolation of hydroclimatic contributions has potential applications to other lakes. Moreover, the results of the study should be useful for local water resources management under climate change.

Acknowledgements. This work is supported by the 973 Program of National Basic Research Program of China (2012CB417003), the State Key Program of National Natural Science of China (41430855), and the Key Program of Nanjing Institute of Geography and Limnology of the Chinese Academy of Sciences (CAS) (NIGLAS2012135001). We thank David Shankman for his constructive comments on an earlier version of the manuscript, R. Guo for data pre-processing, Y. Chen for providing hydrological data, and X. Lai for sharing simulation data from the CHAM-Yangtze model. We are very grateful to Peter Molnar for his inexhaustible patience, critical but constructive comments, and language editing that have substantially improved the manuscript. The anonymous reviewers are acknowledged for their constructive comments on the early version of the manuscript.

Edited by: P. Molnar 


\section{References}

Dracup, J., Lee, K., and Paulson Jr., E.: On the definition of droughts, Water Resour. Res., 16, 297-302, doi:10.1029/WR016i002p00297, 1980.

Environment News Service: China's Largest Freshwater Lake Shrinks in Record Drought, available at: http://ens-newswire.com/2012/01/06/ chinas-largest-freshwater-lake-shrinks-in-record-drought/ (last access: 7 January 2016), 2012.

Feng, H. and Liu, Y.: Trajectory based detection of forest-change impacts on surface soil moisture at a basin scale [Poyang Lake Basin, China], J. Hydrol., 514, 337-346, 2014.

Feng, L., Hu, C., Chen, X.: Satellites capture the drought severity around China's largest freshwater lake, IEEE J-STARS, 5, 12661271, 2012.

Finlayson, M., Harris, J., McCartney, M., Lew, Y., and Zhang, C.: Report on Ramsar visit to Poyang Lake Ramsar site, P. R. China , available at: http://archive.ramsar.org/pdf/Poyang_lake_report_ v8.pdf (last access: 7 January 2016), 2010.

Guo, H., Hu, Q., Zhang, Q., and Feng, S.: Impacts of the Three Gorges Dam on Yangtze River flow and river interaction with Poyang Lake, China: 2003-2008, J. Hydrol., 416-417, doi:10.1016/j.jhydrol.2011.11.027, 2012.

Hayes, M., Svoboda, M., Wall, N., and Widhalm, M.: The Lincoln declaration on drought indices: universal meteorological drought index recommended. B. Am. Meteorol. Soc., 92, 485-488, 2011.

Hervé, Y., Claire, H., Lai, X., Stéphane, A., Li, J., Sylviane, D., Muriel, B.-N., Chen, X., Huang, S., Burnham, J., Jean-François, C., Tiphanie, M., Li, J., Rmié, A., and Carlos, U.: Nine years of water resources monitoring over the middle reaches of the Yangtze River, with ENVISAT, MODIS, Beijing-1 time series, altimetric data and field measurements, Lake Reserv. Manage., 16, 231-247, doi:10.1111/j.1440-1770.2011.00481.x, 2011.

Hu, Q., Feng, S., Guo, H., Chen, G., and Jiang, T.: Interactions of the Yangtze River flow and hydrologic processes of the Poyang Lake, China. J. Hydrol., 347, 90-100, doi:10.1016/j.jhydrol.2007.09.005, 2007.

Jiao, L.: Scientists line up against dam that would alter protected wetlands, Science 326, 508-509, doi:10.1126/science.326_508, 2009.

Kallis, G.: Droughts, Annu. Rev. Environ. Resour., 33, 85-118, doi:10.1146/annurev.environ.33.081307.123117, 2008.

Keskin, F. and Sorman, A.: Assessment of the dry and wet period severity with hydrometeorological index, Int. J. Water Resour. Environ. Engineer., 2, 29-139, 2010.

Keyantash, J. and Dracup, J. A.: The quantification of drought: an evaluation of drought indices, B. Am. Meteorol. Soc., 83, 11671180, 2002.

Kim, H. W., Hwang, K., Mu, Q., Lee, S. O., and Choi, M.: Validation of MODIS 16 global terrestrial Evapotranspiration products in various climates and land cover types in Asia, KSCE J. Civ. Eng., 16, 229-238, 2012.

Kingston, D., Fleig, A., Tallaksen, L., and Hannah, D.: Oceanatmosphere forcing of summer streamflow drought in Great Britain, J. Hydrometeor., 14, 331-344, doi:10.1175/JHM-D-110100.1, 2013.

Lai, X., Jiang, J., Liang, Q., and Huang, Q.: Large-scale hydrodynamic modeling of the middle Yangtze River Basin with complex river-lake interactions, J. Hydrol., 492, 228-243, 2013.
Lai, X., Huang, Q., Zhang, Y., and Jiang, J.: Impact of lake inflow and the Yangtze River flow alternations on water levels in Poyang Lake, China, Lake and Reservoir Management. 30, 321330, 2014a.

Lai, X., Jiang, J., Yang, G., and Lu, X.: Should the Three Gorges Dam be blamed for the extremely low water levels in the middlelower Yangtze River?, Hydrol Process., 28, 150-160, 2014 b.

Liu, Y., Song, P., Peng, J., Fu, Q., and Dou, C.: Recent increased frequency of drought events in Poyang Lake Basin, China: climate change or anthropogenic effects? Hydro-climatology: Variability and Change (IAHS Publ.), 344, 99-104, 2011.

Liu, Y., Zhang, Q., Liu, J., and Li, H.: Climatic, Hydrologic and Environmental Change in Poyang Lake Basin, Science Press, Beijing, 262 pp., 2012 (in Chinese).

Liu, Y., Wu, G., and Zhao, X.: Recent declines of the China's largest freshwater lake: trend or regime shift?, Environ. Res. Lett., 8, 014010, doi:10.1088/1748-9326/8/1/014010, 2013.

Lloyd-Hughes, B. and Saunders, M.: A drought climatology for Europe, Int. J. Climato., 22, 1571-1592, doi:10.1002/joc.846, 2002.

Loarie, S. R., Lobell, D. B., Asner, G. P., Mu, Q., and Field, C. B.: Direct impacts on local climate of sugar-cane expansion in Brazil, Nature Climate Change, 1, 105-9, 2011.

Lomax, R. G.: An Introduction to Statistical Concepts for Education and Behavioral Sciences, Lawrence Erlbaum Associates, Inc. Mahwah, 519 pp., 2001.

McKee, T. B., Doesken, N. J., and Kliest, J.: The relationship of drought frequency and duration to time scales. Proceedings of the 8th Conference of Applied Climatology, 17-22 January, Anaheim, CA, American Meteorological Society, Boston, MA, 179184, 1993.

McKee, T. B., Doesken, N. J., and Kliest, J.: Drought monitoring with multiple time scales. Ninth Conference on Applied Climatology, 15-20 January 1995, Dallas, TX, American Meteorological Society, Boston, MA, 233-236, 1995.

Mendicino, G., Senatore, A., and Versace, P.: A groundwater resource index (GRI) from drought monitoring and forecasting in a Mediterranean climate, J. Hydrol., 357, 282-302, 2008.

Min, Q. and Zhan, L.: Analysis of lake stage relationships between different locations in Poyang Lake, The Yangtze River, 44, 5-10, 2013 (in Chinese).

Mishra, A. and Singh, V.: Review of drought concepts, J. Hydrol., 391, 202-216, doi:10.1016/j.jhydrol.2010.07.012, 2010.

Mishra, A. and Singh, V.: Drought modeling - A review, J. Hydrol., 403, 157-175, doi:10.1016/j.jhydrol.2011.03.049, 2011.

$\mathrm{Mu}, \mathrm{Q}$., Zhao, M., and Running, S. W.: Improvements to a MODIS global terrestrial evapotranspiration algorithm, Remote Sens. Environ., 115, 1781-1800, doi:10.1016/j.rse.2011.02.019, 2011.

Nalbantis, I. and Tsakiris, G.: Assessment of hydrological drought revisited, Water Resour. Manage., 23, 881-897, doi:10.1007/s11269-008-9305-1, 2009.

The Ramsar Convention: The List of Wetlands of International Importance, 25 April 2012, available at: http://www.ramsar.org/pdf/ sitelist.pdf (last access: 7 January 2016), 2012.

Senay, G. B., Leake, S., Nagler, P. L., Artan, G., Dickinson, J., Cordova, J. T., and Glenn, E. P.: Estimating basin scale evapotranspiration (ET) by water balance and remote sensing methods, Hydrol. Process., 25, 4037-4049, doi:10.1002/hyp.8379, 2011.

Shankman, D. and Liang, Q.: Landscape changes and increasing flood frequency in China's Poyang Lake region, 
The Professional Geographer, 55, 434-445, doi:10.1111/00330124.5504003, 2003.

Shankman, D., Keim, B. D., and Song, J.: Flood frequency in China's Poyang Lake region: trends and teleconnections, Int. J. Climatol., 26, 1255-1266, doi:10.1002/joc.1307, 2006.

Sheffield, J., Goteti, G., Wen, F., and Wood, E. F.: A simulated soil moisture based drought analysis for the United States, J. Geophy. Res., 109, D24108, doi:10.1029/2004JD005182, 2004.

Seneviratne, S. L., Lehner, I., Gurtz, J., Teuling, A. J., Lang, H., Moser, U., Grebner, D., Menzel, L., Schroff, K., Vitvar, T., and Zappa, M.: Swiss prealpine Rietholzbach research catchment and lysimeter: 32 year time series and 2003 drought event, Water Resour. Res., 48, W06526, doi:10.1029/2011WR011749, 2012.

Shukla, S. and Wood, A. W.: Use of a standardized runoff index for characterizing hydrologic drought, Geophys. Res. Lett., 35, L02405, doi:10.1029/2007GL032487, 2008.

Smakhtin, V. U.: Low flow hydrology: a review, J. Hydrol., 240, 147-186, 2001

Spinoni, J., Naumann, G., Carrao, H., Barbosa, P., and Vogt, J.: World drought frequency, duration, and severity for 1951-2010, Int. J. Climato., 34, 2792-2804, 2014.

Tallaksen, L. M., Madsen, H., and Clausen, B.: On the definition and modelling of streamflow drought duration and deficit volume, Hydrol. Sci. J., 42, 15-33, 1997.

Tallaksen, L. M. and van Lanen, H. A. J.: Hydrological Droughts: Processes and Estimation Methods for Streamflow and Groundwater, Elsevier Science, Amsterdam, the Netherlands, 576 pp., 2004.

Tan, G., Guo, S., Wang, J., and Lv, S.: Hydrologic Change and Water Resources in Poyang Eco-economic Zone, China Water \& Power Press, Beijing, China, 277 pp., 2013.

Teuling, A. J., Van Loon, A. F., Seneviratne, S. I., Lehner, I., Aubinet, M., Heinesch, B., Bernhofer, C., Grünwald, T., Prasse, H., and Spank, U.: Evapotranspiation amplifies European summer drought, Geophys. Res. Lett., 40, 2071-2075, doi:10.1002/grl.50495, 2013.

Todd, R., Macdonald, N., Chiverrell, R. C., Caminade, C., and Hooke, J. M.: Severity, duration and frequency of drought in SE England from 1697 to 2011, Clim. Chang., 121, 673-687, 2013.

Velpuri, N. M., Senay, G. B., Singh, R. K., Bohms, S., and Verdinb, J. P.: A comprehensive evaluation of two MODIS evapotranspiration products over the conterminous United States: Using point and gridded FLUXNET and water balance ET, Remote Sensing of Environment, 139, 35-49, 2013.
Vicente-Serrano, S. M. and López-Moreno, J. I.: Hydrological response to different time scales of climatological drought: an evaluation of the Standardized Precipitation Index in a mountainous Mediterranean basin, Hydrol. Earth Syst. Sci., 9, 523-533, doi:10.5194/hess-9-523-2005, 2005.

Wan, X. and Xu, X.: Analysis of supply and demand balance of water resources around Poyang Lake, The Yangtze River, 41, 4347, 2010.

Wang, H., Guan, H., Gutiérrez-Jurado, H., and Simmons, C.: Examination of water budget using satellite products over Australia, J. Hydrol., 511, 546-554, 2014.

Wilhite, D. A. and Glantz, M. H.: Understanding the drought phenomenon: the role of definitions, Water Int., 10, 111-120, 1985.

Wilcox, B. P., Huang, Y., and Walker, J. W.: Long-term trends in streamflow from semiarid rangelands: uncovering drivers of change, Glob. Change Biol., 14, 1676-1689, 2010.

Wu, G., Liu, Y., and Zhao, X.: Analysis of spatio-temporal variations of evapotranspiration in Poyang Lake Basin using MOD16 products, Geophysical Research, 32, 617-627, 2013 (in Chinese with English abstract).

Wu, G. and Liu, Y.: Satellite-based detection of water surface variation in China's largest freshwater lake in response to hydroclimatic drought, International Journal of Remote Sensing, 35, 4544-4558, doi:10.1080/01431161.2014.916444, 2014.

Yevjevich, V.: An objective approach to definitions and investigations of continental hydrologic droughts, Hydrology Paper No. 23, Colorado State University, Fort Collins, CO, 18 pp., 1967.

Zelenhasic, E. and Salvai, A.: A method of streamflow drought analysis, Wat. Resour. Res., 23, 156-168, 1987.

Zhang, Q., Li, L., Wang, Y.-G., Werner, A., Xin, P., Jiang, T., and Barry, D.: Has the Three-Gorges Dam made the Poyang Lake wetlands wetter and drier?, Geophys. Res. Lett., 39, L20402, doi:10.1029/2012GL053431, 2012.

Zhang, Q., Ye, X., Werner, A., Li, Y, Yao, J., Li, X., and Xu, C.: An investigation of enhanced recessions in Poyang Lake: Comparison of Yangtze River and local catchment impacts, J. Hydrol., 517, 425-434, 2014.

Zhao, X. and Liu, Y.: Lake fluctuation effectively regulates wetland evapotranspiration: A case study of the largest freshwater lake in China, Water, 6, 2482-2500, 2014. 